\title{
Echocardiographic diagnosis and successful removal of cardiac fibroma in 4-year old child
}

\author{
P C ETCHES, * B GRIBBIN, A J GUNNING
}

From the Department of Paediatrics, the Department of Cardiology, and the Nuffield Department of Surgery, The Radcliffe Infirmary, Oxford

SUMMARY An intramyocardial fibroma shown by echocardiography and angiocardiography was removed from the apex of the left ventricle of an asymptomatic 4-year-old boy.

Primary cardiac tumours are rare and Simcha et al. (1971) found an incidence of 0.08 per cent of all cases of congenital heart disease seen at The Hospital for Sick Children, Great Ormond Street. Fibromas or fibro-hamartomas comprise less than 10 per cent overall (Griffiths, 1965) and occur mostly in children (Geha et al., 1967). The first successful removal of a cardiac fibroma was reported by Parks et al. in 1962, since when this procedure has been more frequently attempted. We report the use of echocardiography to diagnose a left ventricular fibroma in a 4-year-old boy and its subsequent surgical removal.

^Present address: Department of Perinatology, The Children's Hospital, Denver, Colorado, USA.

\section{Case report}

A 4-year-old boy was admitted for investigation when a routine chest $x$-ray film, taken because he was a tuberculosis contact, showed distinct cardiomegaly. His previous history was unremarkable, except that during the two weeks before admission he had lost consciousness on two occasions. Physical examination was normal but the electrocardiogram showed $T$ wave inversion in the anterolateral leads, and echocardiography disclosed gross thickening of the posterior wall of the left ventricle (Fig. 1). At cardiac catheterisation, intracardiac pressures were normal but angiography showed a filling defect at the apex of the left ventricle.

At operation, a hard mass, approximately $60 \times$
Fig. $1 M$-mode single crystal echocardiographic sweep from the aortic root to the left ventricle. The posterior wall is grossly thickened.

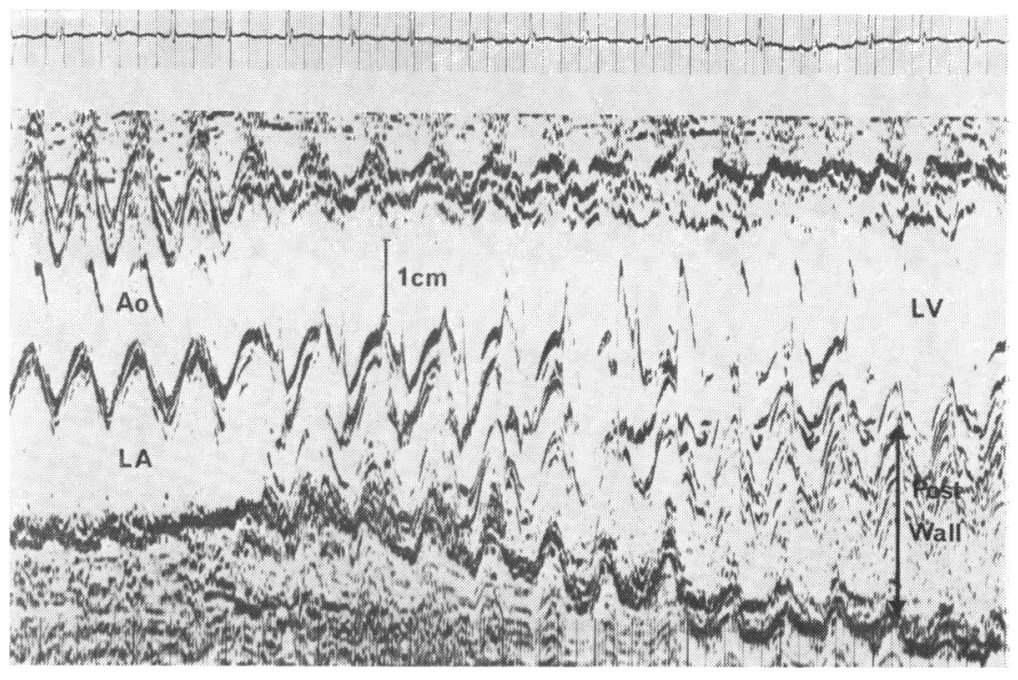




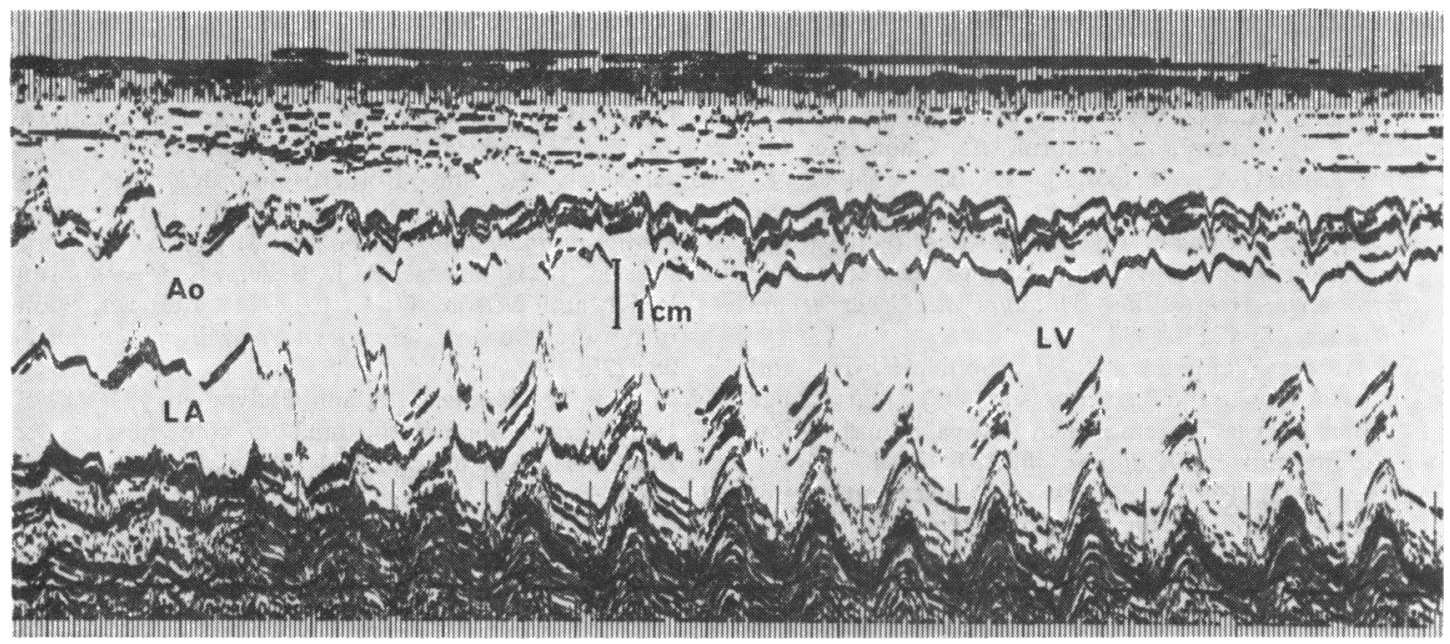

Fig. 2 Twenty-one months after operation the appearances are normal.

$45 \mathrm{~mm}$, was found occupying the posterolateral aspect of the apical portion of the left ventricle. Frozen sections of biopsies from the mass had the appearance of a benign fibroma. The patient was then put on to bypass and the tumour enucleated from the myocardium with the aid of sharp dissection. Closure of the resultant defect in the myocardium did not reduce the left ventricular volume and the heart was beating throughout the procedure.

The removed specimen was a rubbery greyish white tumour weighing $43 \mathrm{~g}$ and measuring $58 \times$ $48 \times 35 \mathrm{~mm}$. The cut surface had a whorled appearance with two or three calcified foci up to $2 \mathrm{~mm}$ in diameter. There was no true capsule and the histological appearances were typical of a benign intramyocardial fibroma. Postoperative recovery was satisfactory and a repeat echocardiogram showed apparently normal left ventricular dimensions (Fig. 2).

\section{Discussion}

The general clinical and pathological features of cardiac fibromas have been fully reviewed elsewhere (Geha et al., 1967; Soler-Soler and RomeroGonzalez, 1975). Our patient had none of the commonly reported symptoms such as cardiac failure or palpitation though it is possible that the episodes of unconsciousness were initiated by a syncopal attack. Certainly there has been no recurrence postoperatively. The chest $x$-ray film showed a characteristic cardiomegaly but no tumour calcification was seen though this is commonly present (Soler-Soler and Romero-Gonzalez, 1975).
Electrocardiographic changes of $T$ wave depression which have been well described in cases of fibroma (Thomsen et al., 1971; Waaler et al., 1972) were also seen in our patient, but echocardiography provided the most striking demonstration of the tumour. There have been several reports outlining the usefulness of echocardiography in the diagnosis of cardiac tumours (Allen et al., 1974; Farooki et al., 1974) but angiography as in this case seems to offer the best chance of defining the position and extent of the lesion.

Cardiac fibromas have been comprehensively reviewed by Geha et al. (1967), and more recently by Fouchard et al. (1972) who described 58 patients with this form of tumour. Since this review further case reports have appeared giving a total of 79 patients, 65 of whom were children and in 41 of whom an attempt at tumour excision was made with 13 deaths, a mortality rate of 32 per cent. The natural history of these lesions is not known but since the majority present clinically in childhood and the tumour is a rare finding in adults at necropsy, it seems that very few remain completely silent. Though it is a benign, slow growing tumour, it may well produce lethal effects by interference with the conducting system or by causing outflow obstruction to either ventricle. We therefore conclude that the risks of surgery are usually justified.

\section{References}

Allen, H. D., Blieden, L. C., Stone, F. M., Bessinger, F. B., Jr., and Lucas, R. V., Jr. (1974). Echocardiographic demonstration of a right ventricular tumour in a neonate. Fournal of Pediatrics, 84, 854-856. 
Farooki, Z. Q., Henry, J. G., Arciniegas, E., and Green, E. W. (1974). Ultrasonic pattern of ventricular rhabdomyoma in two infants. American fournal of Cardiology, 34, 842-844.

Fouchard, J., Cabrol, C., Cabrol, A., Chomette, G., Fauly-Laubry, C., Tricot, J. L., Le Chalvez, J., Beneton, H., and De Georges, M. (1972). Fibrome du ventricle gauche révélé par des tachycardies ventriculaires opérè avec succès chez une enfant de quatre ans. Archives des Maladies du Coeur et des Vaisseaux, 65, 1321-1333.

Geha, A. S., Weidman, W. H., Soule, E. H., and McGoon, D. C. (1967). Intramural ventricular cardiac fibroma. Successful removal in two cases and review of the literature. Circulation, 36, 427-440.

Griffiths, G. C. (1965). A review of primary tumours of the heart. Progress in Cardiovascular Diseases, 7, 465-479.

Parks, F. R., Jr., Adams, F., and Longmire, W. P., Jr. (1962). Successful excision of a left ventricular hamartoma: report of a case. Circulation, 26, 13161320.

Simcha, A., Wells, B. G., Tynan, M. J., and Waterston, D. J. (1971). Primary cardiac tumours in childhood. Archives of Disease in Childhood, 46, 508-514.

Soler-Soler, J., and Romero-Gonzalez, R. (1975). Calcified intramural fibroma of the left ventricle. European fournal of Cardiology, 3, 71-73.

Thomsen, J. H., Corliss, R. J., Sellers, R. D., Mooring, P. K., and Wilson, W. L. J. (1971). Left ventricular intramural fibroma. American fournal of Cardiology, 28, 726-730.

Waaler, P. E., Svendsen, S., and Halvorsen, J. F. (1972). Intramural calcified fibroma of the heart. Acta Paediatrica Scandinavica, 61, 217-222.

Requests for reprints to Dr B Gribbin, Department of Cardiology, The Radcliffe Infirmary, Oxford OX2 6HE. 